\title{
Developing the Methodology for Effective Teaching of the Russian Language to Migrant Muslim Children
}

\author{
Lera A. Kamalova ${ }^{{ }^{*}}$, Venera G. Zakirova ${ }^{1}$ \\ ${ }^{1}$ Kazan (Volga region) Federal University, Kazan, RUSSIA
}

Received 29 May 2017 - Revised 1 October 2017 - Accepted 11 November 2017

\begin{abstract}
The necessity of this study was determined by the importance of the issue of migrant children's language adaptation. Migrant children are arriving in Russia having no knowledge of the Russian language but at the same time schools and other educational organizations are not prepared to cater to these children - there is a lack of tested methodologies that are evidence-based and effective in teaching Russian as a second language to migrant children. This study was aimed at (1) examining the process of migrant children's language adaptation in the context of primary school education and (2) developing an effective communicative methodology for teaching Russian to migrant Muslim children and helping them adapt. The main research method used in this project was a pedagogical experiment that followed observing-reporting, formative and control stages. We also used statistical analysis and expert evaluations. 152 primary school migrant children took part in our research project. The teaching methodology was designed with respect to positive language transfer (positive crosslinguistic influence) and linguistic interference (negative cross-linguistic influence). The main distinguishing feature of the developed methodology is that it is based on the model that uses three languages in the educational process - going from the native language of children (Uzbek) to Tatar and then transitioning to Russian. Our findings confirmed the effectiveness of the developed methodology as its use helped children significantly improve their Russian with some of them achieving the level B1 in a relatively short period of time. Parents, primary school teachers and other educators might find this article interesting and useful.
\end{abstract}

Keywords: Muslim migrant, language adaptation, bilingual methodology, primary school children, Russian language

\section{INTRODUCTION}

\section{The Importance of the Issue}

In the current situation of growing migration in Russia the issue of migrant children socialization through language adaptation to the host country is becoming more and more pressing. We are witnessing at the moment the increasing numbers of children who have no or very little knowledge of the Russian language.

Migrant children often experience difficulties with forming full, well-structured sentences in Russian: it is difficult for them to link words and phrases into meaningful, logical and grammatically correct speech - the intended meaning often distorted. Moreover, migrant children often do not know how to use linking words appropriately. In view of this their speech is disjointed.

All of this means that migrant children need to be taught in a very particular way that takes into account the issues of bilingualism, ethnic identity and the lack of knowledge of the Russian language.

Another characteristic of the teaching process is that the Russian language becomes a tool to explore the world's culture for migrant children thus through bilingual and multilingual education children interact with three main 


\section{Contribution of this paper to the literature}

- The authors suggest an effective method of teaching Russian to migrant Muslim children based on the communicative approach. This method takes into positive language transfer (positive cross-linguistic influence) and linguistic interference (negative cross-linguistic influence) and involves working with primary children in three languages (their native language (Uzbek), Russian and Tatar) and helping them explore a variety of topics (academic, cultural and every day social topics).

- In the work with children the authors were mainly focused on developing children's speaking and listening skills in view of their main goal - to help children learn to effectively communicate in Russian.

- The authors employed the system of situational dialogues that were designed with the consideration of children's level and facilitate their language acquisition (helping them transition from the beginning and elementary levels (A1 and A2) to the independent level (B1)).

sources: Russian, national (non-Russian) and universal (panhuman). Moreover, the process of teaching Russian to migrant Muslim children needs to be organized with the consideration of positive language transfer and interference: the structure of the Russian language can be learnt through understanding how and in what ways it is similar to their native language. The traditional methodology of teaching Russian through the grammar system of the language is not effective. The main goal in the process of teaching migrant children is to help them acquire solid communication skills that will facilitate their further speech development. In view of this the main methodology employed in teaching Russian to migrant children is bilingual methodology that is based on dialogue communication with the use of three languages.

\section{Russian Pedagogic Literature Review}

Huhlaev (2005), Zasipkin et al. (2012) and Kudryavtseva (2011) wrote on the issue of socio-cultural adaptation through learning the Russian language and culture. These scholars drew attention to the socio-cultural aspects of migrant children's adaptation, proposing the system of psycho-pedagogical sessions that help migrant primary school children adapt and socialize within their school.

Gulyaeva (2010), Korchagina (2010), Zeitlin (2010), Shchukin (2012) study the issue of language adaptation of migrant children and develop effective practices of teaching Russian as a second language. Their works are focused on linguistic aspects of teaching the Russian language: the development of speech (phonemic awareness, linguistic intuition, an ability to imitate and differentiate, etc.) and psychological functions that are related to speech through using role play.

Sineva and Shorina (2009), Sergeeva (2005), Kamalova and Zakirova $(2015,2016)$ wrote about the methods of teaching the Russian language to migrants. These scholars propose enhancing migrants' motivation through careful selection of didactic materials and through engaging them in a system of speech exercises aimed at a communicative and educational development.

Some scholars focus on the language adaptation of bilingual and multilingual children looking into how this process gets influenced by linguistic interference (Protasova and Rodina, 2015; Lebedeva and Rozova, 2016), family environment and the level of language proficiency of parents (Madden, 2011). In addition these scholars note that the younger children are the more likely they are to become fully competent in the new language. If children are assisted in developed an ability to speak languages in the correct way then bilingualism (or trilingualism) will not hinder their children's intellectual development. Moreover, for multilingual families it is extremely important to clearly separate one language from another: one parent - one language.

Rosenzweig (2008), Zalevskaya (2009), Gabdulhakov and Khisamova (2012), Kolokol'nikova (2016) studied the issue of interference by looking at how the native language comes into contact with the Russian language. They particularly stress how important it is to take into account positive and negative language transfer when teaching Russian to migrant children especially when helping them master the phonetic system of the Russian language, gender as a linguistic category (female, male, neutral), verb aspects (perfective and imperfective).

In academic literature migrant children are often referred to as bilinguals and speakers of foreign languages. The dictionary of multicultural education defines bilingualism as 'an ability to speak two languages fluently' (Zalevskaya, 2009). Migrant children learn Russian through using their native language - it influences how the Russian language sounds to them (Zalevskaya, 2009). Kolokol'nikova (2015) have been closely working with bilingual children in Tatarstan (who speak Tatar and Russian) observing how they master Russian which is a second language for them. She writes that the main condition for learning Tatar is being submerged into this language... Communication in two languages is the main prerequisite for bilingualism. The language competence becomes higher when home practice of speaking languages in everyday situations is combined with school lessons' (Kolokol'nikova, 2015). 
The desired outcome of language adaptation is fully functional language proficiency. A person achieves full functional language proficiency when he or she can effectively interact with native speakers in any context (Gulyaeva, 2011). Gabdulhakov (2011) stresses that lingustic interference needs to be studied in depth in order to create an adequate language adaptation system. On the level of transposition three languages (Uzbeck, Tatar and Russian) have many similar components: they have nouns, verbs and other parts of speech. In view of this it is not difficult to transfer knowledge from one language to another. For migrants the most difficult parts for learning are those that are completely different from their native language. For example, many migrant learners struggle to understand word genders (female, male, neutral) and verb aspects (perfective and imperfective) (Gabdulhakov and Khisamova, 2012).

\section{Analyzing International Pedagogic Literature}

Kumi-Yeboah and Smith (2016) are studying the issue of cultural and language adaptation. They have identified which factors influence the formation of intercultural competencies in migrant children. Moreover, they have developed a special course for teachers preparing them to work with migrant children. Kumi-Yeboah and Smith (2016) propose organizing the educational process by placing a lot of stress on cultural and language differences because it promotes critical multicultural education of children.

Bojović (2016) is also focused on the language adaptation of develop communicative competencies which enable them to understand native speakers without requiring any assistance. Over the course of lessons students are encouraged to use their language knowledge in real life situations and express their thoughts freely in a second language following grammatical rules. In these lessons students and teachers do not use their native language. They communicate using the phrases and lexical constructions they are already familiar with. In addition to get their message across they use can facials expressions, gestures, audio recordings and demonstration materials.

Sierra (2017), Convertino (2016), Toibekova et al. (2016) share their methodologies of teaching Russian to migrant children. They propose designing new educational progammes for migrant children that (1) take into account their personal, social, family and cultural factors and (2) make use of interactive methods.

Moreover, having reviewed a range of research practices Convertino (2016) proposes using the method of dialogue learning when working with migrants in the context of multicultural education. Dialogue learning involves productive interaction of students and teachers that happens through the process of communication, understanding and collaboratively working on achieving common communicative goals, through making attempts to express one's ideas in multiple ways, through enhancing one's communicative competency in the process of talking to other people.

Toibekova et al. (2016) write about teaching children (through the use of interactive methods and techniques) foreign languages (Russian and English) as tools for international communication which help students explore the world's culture.

The issue of enculturation and acculturation has been thoroughly developed by D. Birman (2016). Her research involved Russian migrants in the USA and her findings show that different orientations on either home or host cultures have different functions depending on specific spheres of life. D. Birman (2016) argues that life satisfaction is connected to and often comes from successful professional adaptation and social support from one's ethnic group. Moreover, language adaptation has direct impact on the process of migrant children's socialization, on their interaction with the new culture and on their identity formation.

Haugen (1972) and Weinreich (2000) looked into how linguistic interference influences the process of learning a new language. Aquino-Sterling and Rodríguez-Valls (2016) develop the issue of bilingual education through studying how migrant children learn Spanish. They have looked into how interference shapes the ability to acquire two or more languages. They have also proposed developing educational programmes and study plans for migrant children in accordance with the principles of bilingual education.

Thus, our literature review shows that the process of language adaptation of migrant children is connected with acculturation, enculturation, the work of teachers (their methods, practices, etc.), study materials and children's environment.

\section{MATERIALS AND METHODS}

\section{Research Objectives}

This research project had the following main objectives: 1) to study theoretical works on language adaptation that are relevant to the topic; 2) to develop a solid theoretical framework for our project; 3) to develop the methodology of dialogue teaching that caters to young Muslim migrant children; 4) to test the developed methodology empirically and analyze the results. 


\section{Theoretical and Empirical Methods}

In order to test our hypothesis we used a set of interrelated and mutually supportive methods:

- theoretical methods: the analysis of relevant pedagogical and psychological works; analysis of methodological and educational literature; theoretical analysis of the developed set of teaching methods that formed the foundation of our hypothesis; theoretical argumentation defending the developed set of teaching methods.

- empirical methods: participant observations, reports, formative and summative assessment, surveys, the analysis of our empirical findings.

\section{Research Facilities}

We conducted our research in the following Tatarstan organizations: Municipal State-funded Educational Institution (MSEI) 'Grammar school №5' (this school has Tatar ethno-cultural orientation), MSEI 'Nurlat comprehensive school'; Zelenodolsk MSEI 'Grammar school №16’ (the main language of instruction in this school is Tatar). All in all, 152 primary school children participated in our research.

\section{Research Stages}

Our research project had three main stages:

The first stage involved preliminary theoretical work, gaining access to the facilities, conducting our observations of primary school migrant children learning Russian in Tatarstan schools, monitoring and analyzing teachers' practices, assessing the Russian language competence of children, conducting questionnaire surveys.

The second stage involved improving our theoretical framework, conducting our educational experiment in MSEI ‘Grammar school №5’, MSEI ‘Nurlat comprehensive school'; Zalenodolsk MSEI ‘Grammar school №16’ (with the total number of participating primary school children 152).

The third stage involved the analysis, generalization and systematization of our findings, at this stage we also presented some of our findings in publications and at academic conferences.

\section{Assessment Criteria}

We assessed the language competence of Muslim migrant children using the Common European Framework of Reference for Languages in which A1 and A2 are basic user levels, B1 and B2 - independent user levels, C1 and C2 - proficient user levels. At different stages of our research migrant children demonstrated levels from A1 to B1. At the level A1 people can understand separate words and short simple phrases in slow and clear speech. This level allows to participate in conversations with others who speak slowly with repetitions and clarifications. This level also allows to ask and answer simple questions within a limited range of topics, especially topics that are important to the learner (for instance, about school, family, shopping, etc.). At the level A2 learners can comprehend simple and short announcements and messages and they can deal with familiar situations giving short replies but cannot lead conversations themselves. At the level B1 people can understand simple and clear speech. They can deal with familiar situations and give appropriate replies to simple questions. They can also describe their experiences, feelings and ideas.

\section{Empirical Procedure}

The empirical part of our research project took place in three schools in Tatarstan: MSEI ‘Grammar school №5’ (58 children took part in our project), MSEI 'Nurlat comprehensive school' ( 40 children took part in our project); Zalenodolsk MSEI ‘Grammar school №16' (54 children took part in our project). The total number of participating migrant children was 152. The analysis of study books and study guides that are used in these schools showed that migrant children are predominantly taught with the use of 'the School of Russia' - the study complex that was designed for children whose first language is Russian. These schools do not have any study materials that were specifically designed for migrant children.

\section{RESULTS}

\section{Observing and Reporting Stage of the Pedagogical Experiment}

In order to conduct this part of our research we selected two groups of primary school migrant children. The first group (experimental group) consisted of 102 children ( 22 children were in 1 grade, 23 children - in 2 grade, 25 
Table 1. The results of the control group at the observing and reporting stage

\begin{tabular}{|c|c|c|c|c|}
\hline Verbal abilities & 1 grade & 2 grades & 3 grade & 4 grade \\
\hline Topic and situation comprehension & $\begin{array}{c}2 \text { children } \\
16.6 \%\end{array}$ & $\begin{array}{c}1 \text { child } \\
10 \%\end{array}$ & $\begin{array}{c}1 \text { child } \\
6.6 \%\end{array}$ & $\begin{array}{c}2 \text { children } \\
15.3 \%\end{array}$ \\
\hline Know-how to make up dialogues on the required topic & $\begin{array}{c}2 \text { children } \\
16.6 \% \\
\end{array}$ & $\begin{array}{c}1 \text { child } \\
10 \%\end{array}$ & $\begin{array}{c}1 \text { child } \\
6.6 \%\end{array}$ & $\begin{array}{c}2 \text { children } \\
15.3 \%\end{array}$ \\
\hline Know-how to follow a speech pattern example & $\begin{array}{l}1 \text { child } \\
16.6 \%\end{array}$ & $\begin{array}{c}1 \text { child } \\
10 \%\end{array}$ & $\begin{array}{c}1 \text { child } \\
6.6 \%\end{array}$ & $\begin{array}{c}1 \text { child } \\
7 \%\end{array}$ \\
\hline
\end{tabular}

Table 2. The results of the experimental group at the observing and reporting stage

\begin{tabular}{|c|c|c|c|c|}
\hline Verbal abilities & 1 grade & 2 grade & 3 grade & 4 grade \\
\hline Topic and situation comprehension & $\begin{array}{c}2 \text { children } \\
9 \%\end{array}$ & $\begin{array}{c}1 \text { child } \\
4 \%\end{array}$ & $\begin{array}{c}1 \text { child } \\
4 \%\end{array}$ & $\begin{array}{c}3 \text { children } \\
9.3 \%\end{array}$ \\
\hline Know-how to make up dialogues on the required topic & $\begin{array}{c}2 \text { children } \\
9 \%\end{array}$ & $\begin{array}{c}1 \text { child } \\
8.5 \%\end{array}$ & $\begin{array}{c}1 \text { child } \\
4 \%\end{array}$ & $\begin{array}{c}2 \text { children } \\
6.2 \%\end{array}$ \\
\hline Know-how to follow a speech pattern example & $\begin{array}{c}2 \text { children } \\
9 \%\end{array}$ & $\begin{array}{c}2 \text { children } \\
8.5 \%\end{array}$ & $\begin{array}{c}1 \text { child } \\
4 \%\end{array}$ & $\begin{array}{c}2 \text { children } \\
6.2 \%\end{array}$ \\
\hline
\end{tabular}

children - in 3 grade, 32 - in 4 grade). The second group (control group) had 50 children (with 12 children being in 1 grade, 10 children - in 2 grade, 15 children - 3 grade, 13 children - in 4 grade). Both groups were assessed to establish their initial levels of Russian (their listening and speaking skills were assessed). First graders were given an assignment to make up a dialogue in Russian that would contain 2 or 3 sentences on the topic 'Meeting new people' and then children had to perform this dialogue with their classmates. Second graders had a similar task but were expected to use 3-4 sentences on the topic 'My classmates'. The same task was given to third graders using 4 sentences on the topic 'My favorite activity'. Finally, children in fourth grade were expected to make up a dialogue out of 5 sentences on the topic 'On the street' and then they also performed it with their classmates. The results of this stage are presented in full in the tables below.

The results of the assessment of the experimental group at this stage are detailed in full in the Table 1.

At this stage the children of the control group demonstrated poor competence in the Russian language children could understand familiar words and very short simple phrases when being spoken to in a slow and clear manner.

The results of experimental group are different and they are presented in Table 2.

At this stage the children of the experimental group also demonstrated the beginner's level of Russian - children could talk about familiar places and people using very short simple phrases (participating in dialogues using no more than one sentence).

This part of our research showed that migrant children in both control and experimental groups had low level of communicative competences. In the course of our assessment we established that all the participants demonstrated the level A1 - poor competence in the Russian language. Moreover, this assessment enabled us to identify the most common difficulties in learning Russian: the phonetic system of the Russian language; word genders and cases; animate and inanimate nouns; aspectual-temporal relations; word order in a sentence.

\section{Formative Stage of the Pedagogical Experiment}

The main goal of this part of our project was to teach migrant children to comprehend real life conversations of native Russian speakers and to engage in them adequately - to freely converse with others in Russian on a variety of topics (including those related to school, culture, every day social encounters).

This part of our research project took place between September 2016 and February 2017 engaging children from the experimental group (102 children). The Russian lessons and supplementary Russian classes that the experimental group received were based on our original communicative methodology that uses interactive study materials 'Dialogues with migrant children'.

Our original teaching methodology was specifically designed for migrant children learning Russian and has a number of specific characteristics. In the process of teaching migrant children we took into account the phenomenon of transposition (positive influence of one language to another) and the phenomenon of interference (negative influence of one language to another). Considering transposition and interference we developed 26 dialogues for migrant children using three languages (Uzbek - their native language, Tatar and Russian) on academic, cultural and every day social topics which formed a unified system of Russian dialogue learning. The dialogues that we developed are communicatively motivated, situation specific, contain useful information and cultural materials. The following mechanism was used to design these dialogues: each sentence first is given in the native language of 
migrant children (Uzbek) then it is given in Tartar and finally - in Russian. This order was chosen because Uzbek and Tatar come from the same family of languages and share a lot of linguistic similarities (both languages are genderless, they do not have certain prepositions such as in front of, about, etc.). When using our dialogues in lessons we focused on developing children's listening and speaking skills in view of our main goal for this part of the project.

Prior to each dialogue a phonetic warm-up session is offered (articulation exercises, vocabulary and grammatical tasks). The main study materials however are topical dialogues - they are central to all lessons. Teachers assess the quality of speech using the following criteria: speech pace, pauses, the number of sentences relevant to the topic, clarity of speech, the level of elaboration and the variety of structural patterns. For the first grade we selected the following topics: 'Meeting new people', 'My classmates', 'Shopping', 'On the street', 'My favorite activity'. To the second graders we offered the following topics: 'Meeting new people', 'My classmates', 'My family', 'Shopping', 'On the street', 'My favorite activity'. In the third grade the following topics were used: 'Telling people about oneself', 'My friend', 'My family', 'My classmates', 'Learning Russian', 'My school day', 'On the street'. The fourth grade children were offered dialogues on: 'My family', 'My interests', 'Health', 'Weather', 'My home town', 'Cosmonauts', 'The victory day'. Each Russian lesson organized the work of children in pairs and in small groups. Moreover, children helped each other with the pronunciation of Russian words and expressions.

\section{Control Stage of the Experiment}

This part of our research project took place in February 2017 and its main goal was to re-assess the competence in Russian of the children.

Both experimental and control groups (with 102 and 50 children respectively) were given a number of tasks testing their listening and speaking skills. The first (listening) assessment task for the 1 grade children was as follows: 'Please listen to the story "What I love" written by Nosov and then say if the main character can be described as rude'. The second (speaking) task was: 'Please read the following questions: (a) What are you going to do at home? (b) I am in the first grade and what about you? (c) Could you please pass those paints? The tasks were considered successfully completed if children gave an appropriate reply ( 1 or 2 sentences). The first task for the second graders required them to listen to the story 'The Elephant' written by Kuprin and identify the main idea in this story. Then the children were given a speaking task: 'Imagine that you got sick. Please make up a dialogue appropriate for the situation. You need to tell your doctor how you feel and what happened to you and your doctor has to ask you questions and tell you what to do'. This speaking task was considered successfully completed if the dialogues had at least 3 sentences. The listening task for the 3 grade children was as follows: 'Please listen to the story "Philippok" written by L. N. Tolstoy and say what is your opinion of the main character'. The second (speaking) task was as follows: 'Imagine you are lost in an unfamiliar city. You see passers-by on the street who ask you what has happened to you and you are replying to their questions. One passer-by gives you directions how to get to the centre of the city. Please make up an appropriate dialogue for this situation'. This task was considered successfully completed if the dialogues consisted of at least 4 appropriate sentences. The listening task for the 4 grade children was as follows: 'Please listen to the story "The hat that came to life" written by Nosov and share your opinion about the narrator'. The speaking task required the 4 graders to read the following description of the situation and make up an appropriate dialogue: 'Imagine you are at the Maslenitsa festival. There are both adults and children present at the festival. You need to talk to two children there (a boy and a girl) and find out what this festival is about - why and how it is celebrated in Russia'. This task was considered successfully completed if the dialogue had 5-6 sentences. All of the speaking tasks were designed to assess children's abilities to participate in dialogues and to make up dialogues for specific situations. The listening tasks aimed to assess if children could comprehend audio-materials and if they could retell what they heard and offer their own opinion on the topic in at least 2-3 sentences.

The results of the experimental group at this stage indicate that the younger the child the higher his or her level of Russian. Children are acquiring both listening and speaking skills simultaneously.

The results of this stage are presented in full in the tables below.

The results of the assessment of the experimental group (at the level A1) are detailed in full in the Table 3.

The first graders mastered the phonetic system of the Russian language quickly and managed to complete their task. $13.5 \%$ of children demonstrated the level A1 which shows how quickly and effectively can acquire the ability to use spoken Russian. At the same time $43 \%$ of 4 graders also demonstrated the same level. Many children from this age group could only participate in dialogues when their partners slowly repeated and sometimes rephrased their lines. They could also ask and respond to simple questions within the range of familiar topics. 
Table 3. Speech development assessment for the children in the experimental group For the Level A1

\begin{tabular}{|c|c|c|c|c|c|c|c|c|}
\hline \multirow{2}{*}{$\begin{array}{c}\text { Level } \\
\mathrm{A} 1\end{array}$} & \multicolumn{4}{|c|}{ Listening skills } & \multicolumn{4}{|c|}{ Speaking skills } \\
\hline & 1 grade & 2 grade & 3 grade & 4 grade & 1 grade & 2 grade & 3 grade & 4 grade \\
\hline Russian & 3 children & 4 children & 5 children & 7 children & 3 children & 4 children & 5 children & 10 children \\
\hline Percent & $13.5 \%$ & $17.3 \%$ & $20 \%$ & $22 \%$ & $13.5 \%$ & $17.3 \%$ & $20 \%$ & $43 \%$ \\
\hline
\end{tabular}

Table 4. Speech development assessment for the children in the experimental group For the Level A2

\begin{tabular}{ccccccccc}
\hline Level & \multicolumn{4}{c}{ Listening skills } & \multicolumn{3}{c}{ Speaking skills } \\
\hline A2 & 1 grade & 2 grade & 3 grade & 4 grade & 1 grade & 2 grade & 3 grade & 4 grade \\
\hline Russian & 5 children & 6 children & 9 children & 14 children & 5 children & 7 children & 12 children & 15 children \\
\hline Percent & $23 \%$ & $40 \%$ & $30 \%$ & $30 \%$ & $27 \%$ & $33 \%$ & $40 \%$ & $37 \%$ \\
\hline
\end{tabular}

Table 5. Speech development assessment for the children in the experimental group For the Level B1

\begin{tabular}{|c|c|c|c|c|c|c|c|c|}
\hline \multirow{2}{*}{$\begin{array}{c}\text { Level } \\
\text { B1 }\end{array}$} & \multicolumn{4}{|c|}{ Listening skills } & \multicolumn{4}{|c|}{ Speaking skills } \\
\hline & 1 grade & 2 grade & 3 grade & 4 grade & 1 grade & 2 grade & 3 grade & 4 grade \\
\hline Russian & 14 children & 13 children & 11 children & 11 children & 14 children & 12 children & 8 children & 7 children \\
\hline Percent & $63.5 \%$ & $42.7 \%$ & $50 \%$ & $48 \%$ & $59,5 \%$ & $49.7 \%$ & $40 \%$ & $23 \%$ \\
\hline
\end{tabular}

Table 6. Language levels in the experimental group

\begin{tabular}{|c|c|c|c|c|}
\hline Language levels & 1 grade & 2 grade & 3 grade & 4 grade \\
\hline Level A1 & $13, .5 \%$ & $17.3 \%$ & $20 \%$ & $40 \%$ \\
\hline Level A2 & $27 \%$ & $33 \%$ & $40 \%$ & $37 \%$ \\
\hline Level B1 & $59.5 \%$ & $49.7 \%$ & $40 \%$ & $23 \%$ \\
\hline
\end{tabular}

The results of the assessment of the experimental group (at the level A2) are detailed in full in the Table 4.

$23 \%$ of first graders, $40 \%$ of third graders and $37 \%$ of four graders demonstrated the level A2. Children could communicate within simple and familiar situations. They could participate in a short conversation on a limited range of topics but were not able to dominate conversations themselves.

The results of the assessment of the experimental group (at the level B1) are detailed in full in the Table 5.

Primary school children demonstrated that they could communicate in the majority of simulated situations without having any preparation (albeit within the range of familiar topics). First graders showed the highest results $(59.5 \%)$, second and third graders demonstrated adequate results (49.7\% and $40 \%$ accordingly) and fourth graders had the lowest results of all $(22 \%)$.

The results of the control group revealed that the children had lower levels of language skills in comparison to the experimental group and within the levels A1-A2. The results of this group are detailed in Table 6.

No one in this group managed to achieve the level B1 - all of the children demonstrated the basic level of Russian. They could understand separate familiar words and very simple phrases in slow clear speech.

Based on these results we conclude that the youngest children in the experimental group ( 1 and 2 graders) go through language adaptation fairly quickly because the processes of enculturation (the process of learning the new culture and social norms) and acculturation (the process of accepting the new culture and following the new social norms) happen for them as one process (simultaneously). Language adaptation was happening not so quickly for older children (4 graders) because for them the process of enculturation was dominating over the process of acculturation. The developed methodology proved to be effective.

\section{DISCUSSIONS}

In the course of this research project we managed to achieve the following results: the experiment group of migrant children managed to significantly improve their levels of Russian in relatively short period of time through being taught with the use of the developed methodology along with the use of our original study materials 'Dialogues with migrant children'; the children became interested in the Russian language; the conditions for further effective learning were created; the children improved their listening and speaking skills and got familiar with a wider range of topics. In view of this we came to the conclusion that Russian lessons need to be organized in accordance with the following model: Native language (Uzbek) - Tatar language - Russian language. This order 
of languages was chosen in view of the fact that Uzbek and Tatar come from the same language family (Turkic language group).

We conclude that listening activities can not only be a source of language knowledge but also a source of sociocultural knowledge which facilitate the effective adaptation of migrant children and their integration into Russian society.

We identified typical situations in which auditory perception plays the most important role in the conversational situation. The migrant children acquired the basic understanding of semantic and syntactic structures in the Russian language. They extended their vocabularies and enhanced their ability to converse in Russian which is necessary to prepare them for further educational stages.

\section{CONCLUSION}

In the course of our study we developed a dialogue-based bilingual methodology that helps migrant primary school children acquire Russian through learning in three languages (their native (Uzbeck), Russian and Tatar). This makes it possible for children to master Russian by using their native language and also similar to it - Tatar. Positive language transfer (positive cross-linguistic influence) and linguistic interference (negative cross-linguistic influence) were taken into account.

The developed methodology is based on two speech activities: speaking and listening which facilitates optimal conditions for the rapid learning of spoken Russian.

The developed situation-based dialogues, that cover most common for this age group topics (academic, social and cultural), was very useful in helping children learn and transition from the basic (A1 and A2) to independent levels (B1) of Russian.

All in all, we developed an interactive methodology teacher support materials 'Dialogues with migrant children' in which all dialogues are supplemented with phonetic warm-ups, articulation exercises, vocabulary and grammatical tasks.

The work is performed according to the Russian Government Program of Competitive Growth of Kazan Federal University.

\section{ACKNOWLEDGEMENT}

The work is performed according to the Russian Government Program of Competitive Growth of Kazan Federal University.

\section{REFERENCES}

Aquino-Sterling, C. R., \& Rodríguez-Valls, F. (2016). Developing Teaching-Specific Spanish Competencies in Bilingual Teacher Education: Toward a Culturally, Linguistically, and Professionally Relevant Approach. Multicultural Perspectives, 18(2), 73-81.

Birman, D. (2016). Minority students' psychological adjustment in the school context: an integrative review of qualitative research on acculturation. Intercultural Education, 27(1), 1-21.

Bojović, Z. (2016). Teaching the children of migrants and refugees. Arset Humanitas, 10(2), 149-160.

Convertino, C. (2016). Beyond Ethnic Tidbits: Toward a Critical and Dialogical Model in Multicultural Social Justice Teacher Preparation. International Journal of Multicultural Education, 18(2), 125-142.

Dictionary of Foreign Words Russian Language. (2011). Retrieved from http://www.onlinedics.ru/slovar/inyaz.html

Gabdulchakov, V. F. (2011). Of linguistic education in kindergartens. International Journal of Early Years Education, 19(2), 185-188.

Gabdulhakov, V. F., \& Khisamova, V. N. (2012). Linguodidactics multicultural education. Moscow: Academia.

Gulyaeva, A. N. (2010). Sotsiokulturnaya adaptation of migrant children. Psychological Science and Education, 5, 158166.

Haugen, E. (1972). The Ecology of Language. Essays by Einar Haugen, selected and introduced by A. S. Dil. Standford: Stanford University Press.

Huhlaev, O. E. (2005). Not like everything: psychological adaptation of migrant children from the cultural environment in elementary school (materials to training). School Psychology, 18(352), 35-38. 
Kamalova, L. A., \& Sakirova, V. G. (2016). Methods of Work with Pupils-Immigrants at Russian Language Lessons in Primary School. International Journal of Environmental and Science Education, 11(14), 6457-6472.

Kamalova, L. A., \& Sakirova, V.G. (2015). Peculiarities of Teaching the Russian Language to Children of Immigrants. International Journal of Environmental and Science Education, 10(6), 921-939.

Kolokol'nikova, Z. U. (2015). The formation of bilingualism in the family under Tatar-Russian and Russian-Tatar bilingualism. Siberian Bulletin Special Education, 1(14), 55-57.

Korchagina, E. L. (2010). Russian language: a successful start - good finish. Publishing house: Russian language Courses.

Kudryavtseva, T. S. (2011). On the problem of cultural adaptation of the speech migrant children. Elementary School, 5, 86-89.

Kumi-Yeboah, A., \& Smith, P. (2016). Critical multicultural citizenship education among black immigrant youth: Factors and challenges. International Journal of Multicultural Education, 18(1), 158-182.

Lebedeva, E. D., \& Rozova, O. G. (2016). Phonetic interference sonorous consonants in Russian language Hungarian students (I certification level). Philology and Linguistics, 2, 17-19.

Madden, E. (2011). Our trilingual children. Krasnodar: Zlatoust Publishing House.

Protasova, E. Y, \& Rodina, N. M. (2015). Multilingualism in childhood. Krasnodar: Zlatoust Publishing House.

Rosenzweig, V. Y. (1972). Language contacts: Linguistic issues. Leningrad: The science.

Sergeeva, O. E. (2005). Cheerful steps: teach Russian as a foreign language. Moscow: Russian language.

Shchukin, A. N. (2012). Education speech dialogue in Russian as a foreign language: teaching manual for teachers of Russian as foreign. Moscow: Russian language Courses.

Sierra, J. F. (2017). Immigrant students in compulsory secondary education: pedagogical vulnerability of the educational system. Education, 20(1), 121-140.

Sineva, O. V., \& Shorina, T. A. (2008). The man, his character, the world: study playing. Moscow: Ethnosphere.

Toibekova, B., Torybaeva Z., Abdullina, G., Abilkhairova, Z., Zhorabekova, A., \& Morozova, V. (2016). Designing of polylingual personality formation in a modern comprehensive school. American Journal of Applied Sciences, 13(11), 1119-1128.

Weinreich, U. (2000). Language contacts: status and research issues. Blagoveshchensk: Annunciation of Humanities College of. I.A. Boduenade Courtenay.

Zalevskaya, A. A. (2009). Questions bilingualism psycholinguistic theory. Questions of Psycholinguistics, 10, 10-17.

Zasipkin, V. P, Zborowski, G. E, \& Shuklina, E. A. (2012). Problems of education and social integration of migrant children in the figures and dialogues: Monograph. Khanty-Mansiysk: Publishing House "News of Ugra".

Zeitlin, S. N. (2010). In foreign language the child in the Russian-speaking school. Journal of the Herzen University, 1, 79-85.

\section{http://www.ejmste.com}

